\title{
Expression of CD105 (endoglin) in arteriolar endothelial cells of human endometrium throughout the menstrual cycle
}

\author{
E. G. Zhang, S. K. Smith and D. S. Charnock-Jones* \\ Reproductive Molecular Research Group, Departments of Pathology, and Obstetrics and \\ Gynaecology, University of Cambridge, Cambridge CB2 2SW, UK
}

The cellular mechanisms underlying normal and pathological endometrial bleeding are not well understood, although abnormalities in the structure of endometrial blood vessels may lead to menstrual disorders. Endothelial cells in different organs are heterogeneous and differ in structure, function, antigen composition, metabolic properties and responses to growth factors. Immunostaining was performed with anti-CD105, CD31, CD34 and von Willebrand factor (vWF), and lectin binding with Ulex europaeus agglutinin 1 (UEA 1), Bandeieraea simplicifolia agglutinin 1 (BS 1), Dolichos biflorus agglutinin (DBA) and Peanut agglutinin (PNA) to characterize endothelial cells in human endometrium throughout the menstrual cycle. Serial sections fixed with formalin were stained with primary antibodies and lectins after antigen retrieval. Positive staining for CD31, CD105 and vWF was confined

\section{Introduction}

Endothelial cells lining the inside of blood vessels are heterogeneous and differ in structure, function, antigen composition, metabolic properties and their response to growth factors. Such heterogeneity has been observed not only in different organs, but also in vessels of different calibre within a single organ (McCarthy, 1991; Bicknell, 1993). For example, endothelial cells lining microvessels, such as in brain white matter, are flattened and elongated, whereas endothelial cells lining large vessels, such as the aorta and umbilical veins, appear polygonal. Endothelial cells have distinct morphotypes in different organs so that they can adapt to different microenvironmental needs. Endothelial cells form a tight, continuous layer of cells that act as a barrier in brain, lung and muscular tissues, whereas a discontinuous layer of cells with intercellular gaps and intracellular fenestrae occurs in the endocrine glands and kidney (Augustin et al., 1994). The local microenvironment has great influence on these cells. Moreover, endothelial cells have a differential response to growth factors. Microvascular endothelial cells isolated from human decidua showed no mitogenic response to several classic endothelial growth factors, such as basic fibroblast growth factor

*Correspondence

Email: dscj1@cam.ac.uk to the vascular endothelium. Endothelial expression of CD31 was observed in all types of vessel, including single cells, and strong staining was found during the early proliferative and mid-secretory phases. Anti-vWF stained arterioles and veins, but there was little positive staining of capillaries. In contrast, staining for CD105 was confined to the arterioles. Although anti-CD34 strongly stained endothelial cells of small vessels and capillaries, staining was also observed on some non-endothelial stromal cells. Strong positive staining for UEA 1 was observed in endothelial cells of all types of vessel throughout the menstrual cycle. Binding of PNA, DBA and BS 1 was confined to the apical region of glandular epithelial cells. This study demonstrates that the differential binding of anti-CD31, CD34, CD105, vWF and UEA 1 distinguishes between endometrial populations of endothelial cells.

(bFGF), epidermal growth factor (EGF) and interleukin 4 (IL-4), but were stimulated by vascular endothelial growth factor (VEGF) (Grimwood et al., 1995).

CD105, also known as endoglin, is a $180 \mathrm{kDa}$ homodimeric membrane protein (Gougos and Letarte, 1990), which acts as a receptor for transforming growth factor (TGF)- $\beta 1$ and $-\beta 3$ in vascular endothelial cells (Cheifetz et al., 1992), and is a proliferation-associated antigen CD105 has been located in human vascular endothelial cells of both large and small vessels. In particular, increased immunoreactivity for CD105 has been observed on endothelial cells during wound healing, in embryonic tissues and tumours (Letarte et al., 1995; Thorpe and Burrows, 1995; Bodey et al., 1998). These data indicate that CD105 may play a role in new blood vessel growth (Fonsatti et al., 2000). CD105 knockout mice die by day 11.5 after mating because of defective vascular development. In addition, cardiac defects were observed in homozygous CD105deficient embryos (Arthur et al., 2000). Mutations in the endoglin gene lead to the hereditary haemorrhagic telangiectasia type 1 disease (HHT1 or Osler-Weber-Rendue disease). The disease is characterized by frequent nose bleeds, mucocutaneous telangiectases and arterio-venous malformation in the lung, brain and gastrointestinal tract, leading to recurrent haemorrhage and shunting (Guttmacher et al., 1995). CD105 has also been found on syncytiotrophoblast, extravillous cytotrophoblasts in human placenta 
(St-Jacques et al., 1994; Dagdeviren et al., 1998), and in activated monocytes, tissue macrophages, and erythroid precursors in fetal and adult bone marrow (Gougos and Letarte, 1988; Bühring et al., 1991; Lastres et al., 1992; Robledo et al., 1996).

Ulex europaeus agglutinin 1 (UEA 1), Bandeieraea simplicifolia agglutinin 1 (BS 1), Dolichos biflorus agglutinin (DBA) and Peanut agglutinin (PNA) are lectins that specifically bind to sugar residues located on the cell surface. Human endothelial cells bind specifically to the lectin UEA 1 via L-fucose residues (Hormia et al., 1983). BS 1 binds to $\alpha$-D-galactosyl and $\alpha$-D-galactopyranoside on the surface of primitive endothelial cells surface, whereas DBA binds to $\mathrm{N}$-acetyl-glucosaminyl residues and PNA binds to $\alpha$-D-galactosyl and D-galactosyl neuraminic acid. BS 1, DBA and PNA have been reported to label endothelial cells of some species. BS 1 is a highly reliable marker of murine and pig endothelial cells and DBA binds endothelium in different organs of pigs, including newly derived capillaries (Plendl et al., 1996). PNA has a unique ability to bind murine and pig brain microvascular endothelial cells (Plendl and Sinowatz, 1995; Plendl et al., 1995).

CD31, CD34 and von Willebrand factor (vWF) are classic endothelial markers and are present in a broad range of tissues. CD31, also known as platelet endothelial cell adhesion molecule (PECAM), is an endothelial cell adhesion molecule. CD34 is a cell surface antigen of approximately $110 \mathrm{kDa}$ and is expressed selectively on human haematopoietic progenitor cells and vascular endothelial cells (Fina et al., 1990, Traweek et al., 1991). vWF is an important factor of the blood coagulation system. It facilitates adherence of blood platelets to the injured vessel wall (Sixma and deGroot, 1991). Characterization of endothelial cells in human endometrium has been undertaken previously. CD31 (Rees et al., 1993; Tawia et al., 1993; Nikitenko et al., 2000), CD34 and vWF (Rees et al., 1993; Song et al., 1995; Nikitenko et al., 2000) have been immunolocalized throughout the menstrual cycle. However, comparative conclusions about the distribution of the antigens on endothelial cells could not be made due to variation in the tissue preparation and staging of samples.

The aim of the present study was to characterize the endothelial cells within human endometrium and to identify differences that may have some bearing on functional differences. Endothelial cells were characterized using a panel of eight endothelial markers (anti-CD105, CD31, CD34, vWF, and lectins UEA I, BS 1, DBA and PNA) throughout the menstrual cycle.

\section{Materials and Methods}

\section{Tissue collection and processing}

Ethical committee approval for tissue collection was obtained from Addenbrooke's Hospital NHS Trust, Cambridge and written informed consent was obtained from women undergoing surgery for benign gynaecological conditions. Women with irregular menstrual cycles (25-35 days), those having received exogenous hormones within the past 3 months and those with known identified endometrial abnormalities were excluded from the study. Endometrial samples $(n=18)$ were collected by dilatation and curettage. Tissues were rinsed in PBS, fixed immediately in $10 \%(\mathrm{v} / \mathrm{v})$ buffered formalin for $6-8 \mathrm{~h}$ and embedded in paraffin wax. Sections $(4 \mu \mathrm{m})$ were cut on to slides coated with 3-aminopropyltriethoxy-silane (Sigma, Poole). For frozen sections, tissues were snap-frozen in liquid nitrogen after washing with PBS. Samples were then stored at $-70^{\circ} \mathrm{C}$.

\section{Staging of tissue samples}

Each biopsy was dated on the basis of the histological appearance of haematoxylin-eosin-stained sections (Wells, 1996). All biopsies were evaluated twice without knowledge of the previous results. Samples from six stages were chosen in the present study: early proliferative $(n=3)$, midproliferative $(n=3)$, late proliferative $(n=3)$, early secretory $(n=3)$, mid-secretory $(n=3)$ and late secretory $(n=3)$.

\section{Immunohistochemistry}

Anti-CD31 (Clone JC/70A; Dako, High Wycombe), antiCD34 (Clone QBEND10; Dako) and anti-CD105 (Clone 266; Becton Dickinson, Cowley) were monoclonal mouse anti-human antibodies. Anti-vWF was a rabbit anti-human antibody (F8/86; Dako) (Table 1). Lectins UEA 1 (Vector Laboratories, Peterborough), BS 1 (Sigma), DBA (Sigma) and PNA (Sigma) were biotin-labelled (Table 1). Preliminary experiments were carried out to determine the optimum concentration of primary antibodies that resulted in clear staining with low background.

Samples from one particular stage were chosen for analysis using frozen sections in addition to formalin fixation to determine whether tissue preparation and fixation influenced the sensitivity of immunostaining.

Tissue sections fixed in formalin were deparaffinized in xylene three times, each for $10 \mathrm{~min}$, followed by rehydration through a graded series of ethanol and $\mathrm{dH}_{2} \mathrm{O}$. For all eight markers, slides were pressure cooked for $1 \mathrm{~min}$ in 0.01 mol sodium citrate buffer $\mathrm{I}^{-1}(\mathrm{pH}$ 6.0) to unmask the antigens. For frozen sections, the slides were fixed in cold acetone for $10 \mathrm{~min}$. All sections were then washed in three changes of PBS and the slides were treated with $3 \%(\mathrm{v} / \mathrm{v})$ $\mathrm{H}_{2} \mathrm{O}_{2}$ in methanol for $10 \mathrm{~min}$ to quench endogenous peroxidase. After three washes in PBS for $30 \mathrm{~min}$, the sections were ready for primary antibody labelling.

For immunostaining of anti-CD31, CD34, CD105 and VWF, the sections were blocked by $20 \%$ (v/v) goat serum (Sigma) in $1 \%(\mathrm{w} / \mathrm{v})$ BSA-PBS and incubated with primary antibody at $37^{\circ} \mathrm{C}$ in a humidified chamber for $60 \mathrm{~min}$. The concentrations used for each antibody were as follows: CD31 (0.41 $\left.\mathrm{mg} \mathrm{m}^{-1}\right)$, CD34 (0.05 mg ml-1), CD105 $\left(0.5 \mathrm{mg} \mathrm{m}^{-1}\right)$ and vWF $\left(5.7 \mathrm{mg} \mathrm{m}^{-1}\right)$. Slides were washed in PBS for $30 \mathrm{~min}$ (three changes) before application of the biotinylated secondary goat anti-rabbit antibody (for vWF; Zymed Laboratories, Cambridge Biosciences, Cambridge) 
Table 1. Antibodies and lectins used in this study

\begin{tabular}{|c|c|c|c|c|}
\hline Antigens or lectins & Clone & $\begin{array}{l}\text { Stock concentration } \\
\qquad\left(\mathrm{mg} \mathrm{ml}^{-1}\right)\end{array}$ & Dilution & Supplier \\
\hline CD31 & $\mathrm{JC} / 70 \mathrm{~A}$ & 0.41 & $1: 20$ & Dako \\
\hline CD34 & QBEnd10 & 0.05 & $1: 25$ & Dako \\
\hline CD105 & Clone 266 & 0.5 & $1: 100$ & Phar-Inter \\
\hline von Willebrand factor (vWF) & F8/86 & 5.7 & $1: 200$ & Dako \\
\hline $\begin{array}{l}\text { Ulex europaeus agglutinin I } \\
\text { (UEA 1)-biotinylated }\end{array}$ & NA & 1.0 & $1: 100$ & Vector Laboratories \\
\hline $\begin{array}{l}\text { Bandeiraea simplicifolia agglutinin } \\
1 \text { (BS 1)-biotinylated }\end{array}$ & NA & 1.0 & $1: 100$ & Sigma \\
\hline $\begin{array}{l}\text { Dolichos biflorus agglutinin } \\
\text { (horse gram) (DBA)-biotinylated } \\
\text { Arachis hypogaea (peanut) }\end{array}$ & NA & 1.0 & $1: 100$ & Sigma \\
\hline (PNA)-biotinylated & NA & 1.0 & $1: 100$ & Sigma \\
\hline
\end{tabular}

NA: not applicable.

or goat anti-mouse antibody (for anti-CD31, CD34 and CD105; Zymed) at 1:100 dilution in PBS for 10 min at room temperature. Sections were then washed in PBS three times (10 min each) and antigen detected by the streptavidinconjugate-horseradish peroxidase complex (Zymed). After further washing, antibody binding was visualized by the liquid DAB-plus substrate kit (Zymed). Slides were counterstained using Meyer's haematoxylin.

For detection of lectin binding, sections were incubated with biotinylated UEA 1, BS 1, DBA and PNA $\left(1 \mathrm{mg} \mathrm{ml}^{-1}\right)$ at $1: 100$ dilution in a humidified chamber for $60 \mathrm{~min}\left(37^{\circ} \mathrm{C}\right)$. After washing with PBS, lectin binding was detected using a streptavidin-conjugate-horseradish peroxidase complex (Zymed), following the staining by liquid DAB-plus substrate kit (Zymed).

Negative controls for the immunostaining were carried out as above, except that the primary antibodies were replaced with normal mouse or normal rabbit immunoglobulins. Controls for lectins were performed by adding the competing sugars at $200 \mathrm{mmol} \mathrm{I}^{-1}$ simultaneously with the lectins.

Subjective assessment of immunostaining intensity was based on a four point scale as absent, weak, moderate and strong.

\section{Results}

\section{Distribution of CD31, CD34, CD105 and vWF in human endometrium throughout the menstrual cycle}

Positive staining for CD31, CD34, CD105 and vWF was confined to vascular endothelium and showed an overlapping, but non-identical, staining pattern. Endothelial expression of CD31 was observed in all types of vessel (arteries, veins and capillaries) (Fig. 1a-d). Arteries were identified by being surrounded by whorls of smooth muscle cells and having a smooth profile; veins were identified by the paucity of surrounding smooth muscle cells and as having a large calibre and an irregular profile; and capil- laries were of small calibre. Strong staining was found during both the early proliferative (Fig. 1a,b) and midsecretory phases of the menstrual cycle (Fig 1c,d). Although endothelial cells were immunostained for anti-CD34 in the arteries, veins and capillaries (Fig. 1e), strong staining was associated with small vessels and, in particular, capillaries during both the early proliferative (Fig. 1e,f), and early and mid-secretory phases (Fig. 1g,h). Staining for anti-CD34 was also detected around the glands (Fig. 1f), particularly at the early and mid-proliferative phases. Strikingly, CD105 was distributed predominantly on arteries (Fig. 1k). There was only weak positive staining for anti-CD105 on veins (Fig. 1I). In contrast, anti-vWF tended to stain large vessels, and there was weak or even absent staining of capillaries (Fig. 1n,o). Medium-sized vessels located close to the glands always stained positive for anti-CD31 (Fig. 1b), antiCD34 (Fig. 1f) and anti-vWF (Fig. 1o).

These results are summarized (Table 2). Frozen tissues from the early secretory phase (when strong staining was observed in the material embedded in paraffin wax) were chosen to assess the effect of different tissue preparation and fixation on the sensitivity of immunohistochemistry. Immunohistochemistry for anti-CD34, anti-CD105 and vWF showed similar sensitivity on paraffin wax and frozen sections, whereas immunohistochemistry with anti-CD31 showed good staining on frozen sections (data not shown).

No staining was observed for all relevant negative controls (Fig. 1p). No glandular epithelial staining for these four antibodies was detected at any stage of the menstrual cycle.

\section{Binding of UEA 1, BS 1, DBA and PNA in human endometrium during the menstrual cycle}

Good staining with lectins was observed on sections embedded in paraffin wax and sections fixed in formalin, whereas there was high background in frozen sections.

Endothelial cells in arteries, veins and capillaries from all 

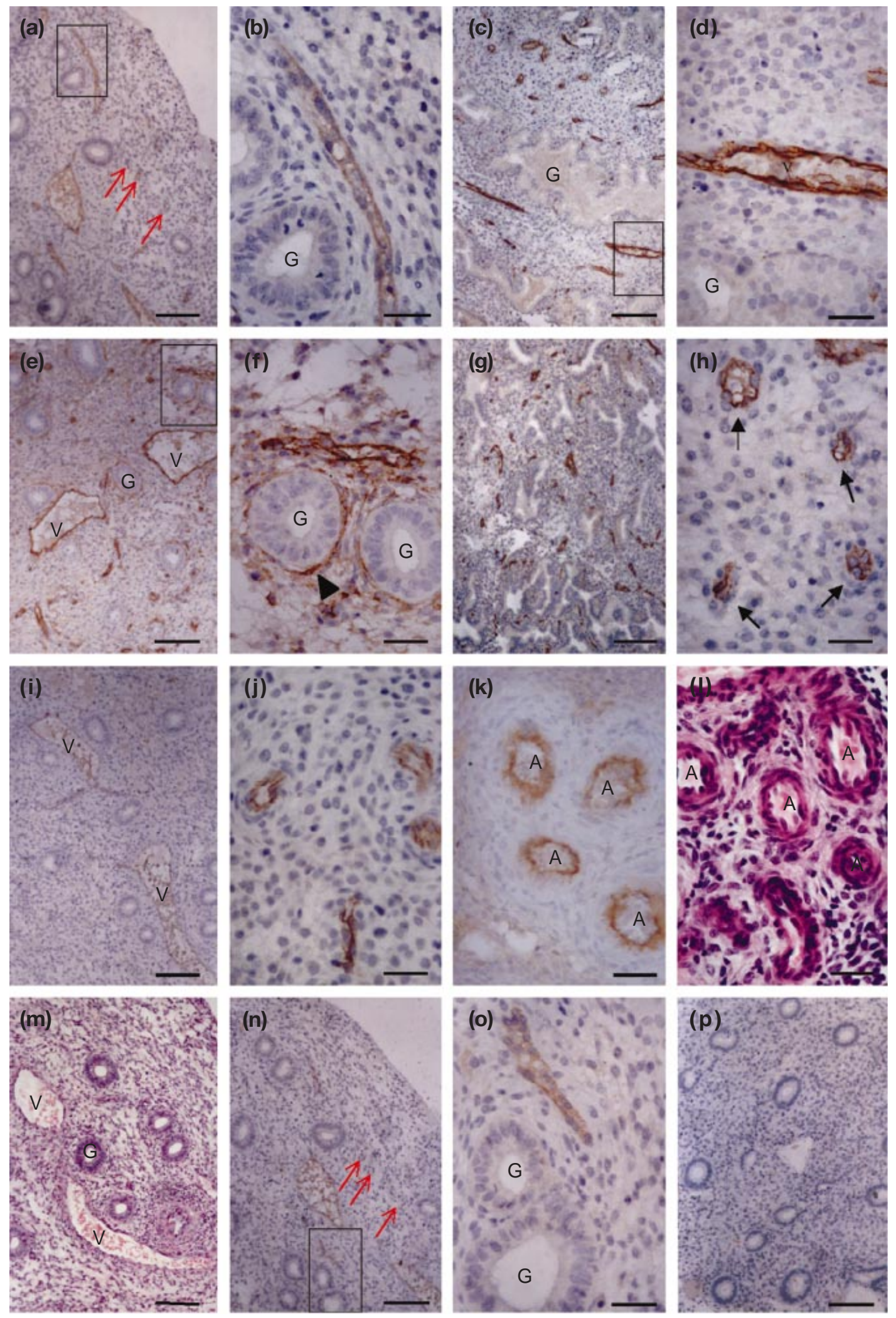

Fig. 1. Reactivity of endothelial cells with anti-CD31, CD34, CD105 and von Willebrand factor (vWF) in human endometrium tissue fixed in formalin and embedded in paraffin wax in $(a, b, e, f, i, j, m-p)$ the early proliferative phase and $(c, d, g, h, k, l)$ the mid-secretory phase of the menstrual cycle. Positive staining for $(a-d)$ CD31, (e-h) CD34, (i-k) CD105 and (n-o) vWF was confined to endothelial cells. (a-d) Anti-CD31 stained all 
Table 2. Reactivity of endothelial cells in human endometrium with antibodies and lectins

\begin{tabular}{|c|c|c|c|c|c|c|c|c|}
\hline \multirow{2}{*}{$\begin{array}{l}\text { Menstrual } \\
\text { phase }\end{array}$} & \multicolumn{4}{|c|}{ Antibodies } & \multicolumn{4}{|c|}{ Lectins } \\
\hline & Anti-CD31 & Anti-CD34 & Anti-CD105 & vWF & UEA 1 & PNA & DBA & BSI \\
\hline \multirow[t]{3}{*}{ Early proliferative $(n=3)$} & $\mathrm{A}++$ & $\mathrm{A}+++$ & $\mathrm{A}++$ & $A+$ & $\mathrm{A}+++$ & $\mathrm{EC}-$ & $\mathrm{EC}-$ & EC - \\
\hline & $\mathrm{V}++$ & $V+++$ & $V+$ & $V+$ & $\mathrm{V}+++$ & $\mathrm{G}+$ & $\mathrm{G}++$ & $\mathrm{G}++$ \\
\hline & $\mathrm{C}+$ & $\mathrm{C}++$ & $\mathrm{C}-$ & $\mathrm{C}-$ & $\mathrm{C}+++$ & & & \\
\hline \multirow[t]{3}{*}{ Mid-proliferative $(n=3)$} & $A+$ & $A+$ & $A+$ & $A+$ & $\mathrm{A}+++$ & $\mathrm{EC}-$ & $\mathrm{EC}-$ & $\mathrm{EC}-$ \\
\hline & $V+$ & $V+$ & $V-$ & $V+$ & $V+++$ & $G+$ & $\mathrm{G}++$ & $\mathrm{G}++$ \\
\hline & $\mathrm{C}+$ & $\mathrm{C}+$ & $\mathrm{C}-$ & $\mathrm{C}-$ & $\mathrm{C}+++$ & & & $\begin{array}{c}\text { Single stromal } \\
\text { cell }++ \text { ? }\end{array}$ \\
\hline \multirow[t]{3}{*}{ Late proliferative $(n=3)$} & $A+$ & $A+$ & $A+$ & $A+$ & $\mathrm{A}+++$ & $\mathrm{EC}-$ & $\mathrm{EC}-$ & EC - \\
\hline & $V+$ & $V+$ & $V-$ & $V+$ & $\mathrm{V}+++$ & $\mathrm{G}+$ & $\mathrm{G}++$ & $\mathrm{G}++$ \\
\hline & $\mathrm{C}+$ & $\mathrm{C}+$ & $\mathrm{C}-$ & $\mathrm{C}-$ & $\mathrm{C}+++$ & & & \\
\hline \multirow[t]{3}{*}{ Early secretory $(n=3)$} & $\mathrm{A}++$ & $\mathrm{A}+++$ & $\mathrm{A}+++$ & $\mathrm{A}++$ & $\mathrm{A}+++$ & $\mathrm{EC}-$ & $\mathrm{EC}-$ & $\mathrm{EC}-$ \\
\hline & $\mathrm{V}+++$ & $V+++$ & $V+$ & $\mathrm{V}++$ & $\mathrm{V}+++$ & $G+$ & $\mathrm{G}++$ & $\mathrm{G}+++$ \\
\hline & $\mathrm{C}+++$ & $\mathrm{C}+++$ & $\mathrm{C}-$ & $\mathrm{C}+$ & $\mathrm{C}+++$ & & & \\
\hline \multirow[t]{3}{*}{ Mid-secretory $(n=3)$} & $\mathrm{A}+++$ & $\mathrm{A}++$ & $A+$ & $A+$ & $\mathrm{A}+++$ & $\mathrm{EC}-$ & $\mathrm{EC}-$ & $\mathrm{EC}-$ \\
\hline & $V+++$ & $V++$ & V- & $V+$ & $V+++$ & $\mathrm{G}+$ & $\mathrm{G}++$ & $\mathrm{G}+++$ \\
\hline & $\mathrm{C}+++$ & $\mathrm{C}++$ & $\mathrm{C}-$ & $\mathrm{C}-$ & $\mathrm{C}+++$ & & & \\
\hline \multirow[t]{3}{*}{ Late secretory $(n=3)$} & $A+$ & $\mathrm{A}++$ & $A+$ & $A+$ & $\mathrm{A}+++$ & $\mathrm{EC}-$ & $\mathrm{EC}-$ & $\mathrm{EC}-$ \\
\hline & $V++$ & $V++$ & $V-$ & $V+$ & $V+++$ & $\mathrm{G}+$ & $\mathrm{G}++$ & $\mathrm{G}++$ \\
\hline & $\mathrm{C}+$ & $\mathrm{C}+$ & $\mathrm{C}-$ & $\mathrm{C}-$ & $\mathrm{C}+++$ & & & \\
\hline \multirow{3}{*}{$\begin{array}{l}\text { Frozen section } \\
\text { (early secretory) }\end{array}$} & $\mathrm{A}+++$ & $\mathrm{A}+++$ & $\mathrm{A}++$ & $\mathrm{HB}$ & $\mathrm{HB}$ & $\mathrm{EC}-$ & $\mathrm{EC}-$ & $\mathrm{EC}-$ \\
\hline & $V+++$ & $V+++$ & $V+$ & & & $\mathrm{G}+$ & $G+$ & $\mathrm{G}+$ \\
\hline & $\mathrm{C}+++$ & $\mathrm{C}+++$ & $\mathrm{C}-$ & & & $\mathrm{HB}$ & $\mathrm{HB}$ & $\mathrm{HB}$ \\
\hline
\end{tabular}

$(-)$ : no staining; $(+)$ : weak staining; $(++)$ : moderate staining; $(+++)$ : intensive staining.

A: artery; V: vein; C: capillary; EC: endothelial cells; G: gland; HB: high background; vWF: von Willebrand factor; UEA 1: Ulex europaeus agglutinin 1; PNA: Peanut agglutinin; DBA: Dolichos biflorus agglutinin; BSI: Bandeieraea simplicifolia agglutinin.

stages of the menstrual cycle stained intensely with UEA 1 (Fig. 2b,d,e,f). In contrast, binding of BS 1, DBA and PNA was restricted to the apical region of glandular epithelial cells (Fig 2g-i). No endothelial staining with these three lectins was observed in human endometrium. Relevant negative controls resulted in no staining of any type of cell (Fig. 2j).

\section{Discussion}

The present study demonstrated that the distribution of CD105, CD31, CD34, vWF and UEA 1 binding sites differs among populations of endometrial endothelial cells, and, in contrast to that in other species, binding of BS 1, DBA and PNA in humans was restricted to the glandular epithelial cells.

The most marked observation in the present study was that staining for CD105 was confined to arterial endothelial cells. CD105 is a receptor for TGF $\beta 1$ and - $\beta 3$ (Cheifetz et al., 1992). It does not show signalling activity by itself but functions as a regulator to modulate the access of TGF $\beta$ to the signalling complex (Wrana et al., 1994). TGF $\beta$ is chemotactic for monocytes and macrophages, and stimulates angiogenesis in the rabbit cornea (Eisenstein, 1991; Klagsbrun and D'Amore, 1991). It enhances VEGF-induced tube formation of endothelial cells on a collagen gel at low concentrations, but inhibits tube formation at higher concentrations (Pepper et al., 1993). Immunoreactivity of TGF$\beta 1,-\beta 2$ and $-\beta 3$ has been located in glands and stroma in normal human endometrium (Gold et al., 1994) and TGF $\beta$ increases matrix metalloproteinase concentrations in endometrial stroma (Bruner et al., 1995). TGF $\beta$ mRNA content is higher in the secretory phase than in the proliferative phase of the menstrual cycle (Kauma et al., 1990). In the early proliferative phase, spiral arteries have thin walls and are

types of vessel. (b,d,f) Higher magnification of the boxed sections in (a,c,e, respectively). (f) The arrowhead indicates that positive staining was also around the gland. (g,h) Intensive staining for CD34 was associated with small vessels and capillaries. (h) Higher magnification shows capillaries (indicated by arrows) stained with anti-CD34. Endothelial cell expression of CD105 was predominantly in arteries (as shown in (j) and (k)), with weak staining on veins (as shown in (i)). (l) Haematoxylin-eosin staining of a nearby slide of (k) reveals the vessel structure. (n) Immunostaining of VWF shows positive staining on the large vessels, whereas staining was absent from capillaries (indicated by arrows), which stained positively for CD31, as indicated by arrows in (a). (o) Higher magnification of the boxed section in ( $\mathrm{n}$ ). (m) Haematoxylin-eosin staining of a nearby section of (a,e,i,n). (p) Negative control for (a). The negative controls for CD34, CD105 and vWF were similar to (p), data not shown. Scale bars represent (a,c,e,g,i,m,n,p) $50 \mu \mathrm{m}$ and (b,d,f,h,j,k,l,o) $12.5 \mu \mathrm{m}$. G: glands; A: arteries; V: veins. 

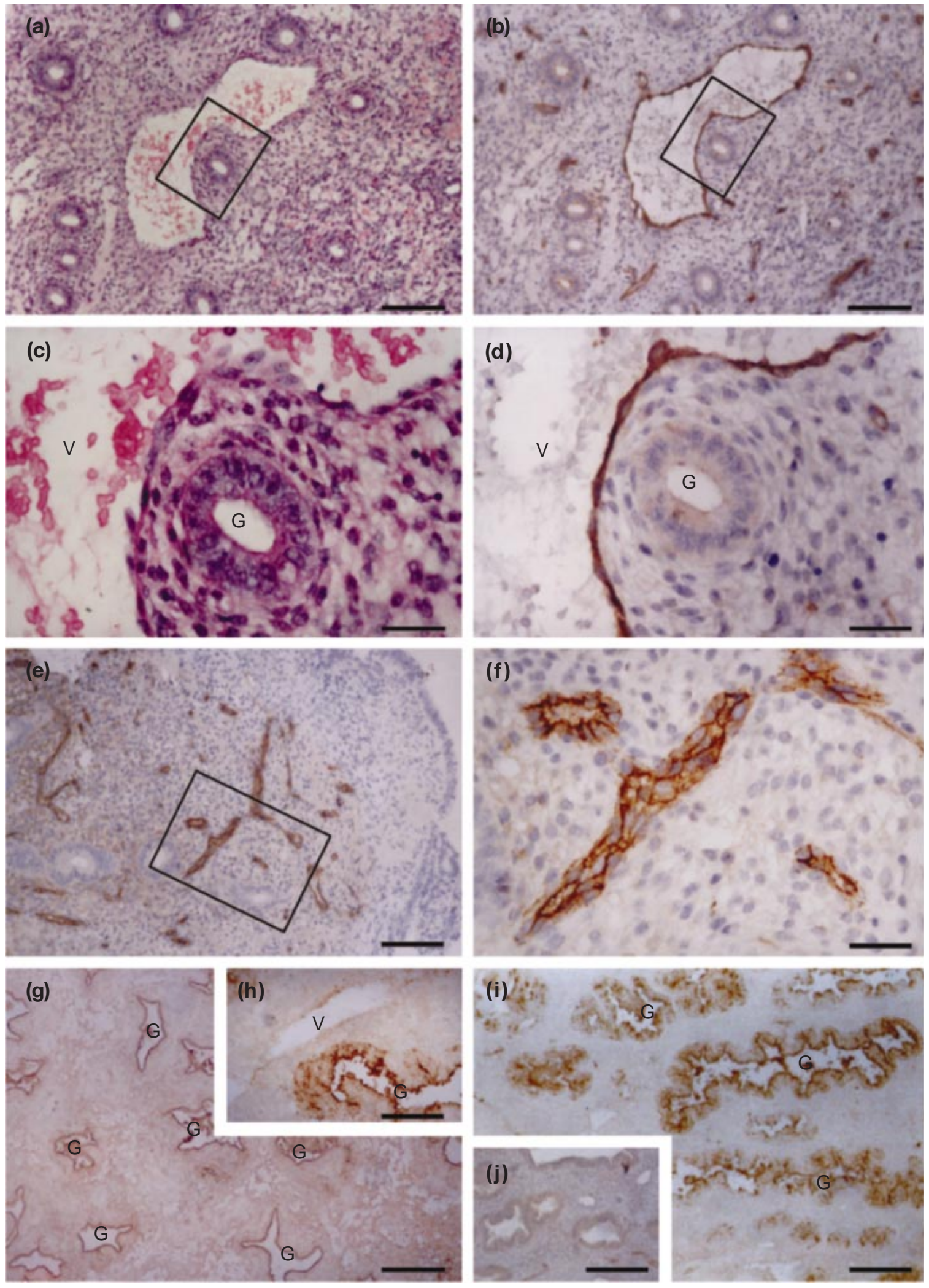

Fig. 2. Reactivity of endothelial cells with Ulex europaeus agglutinin 1 (UEA 1), Peanut agglutinin (PNA), Dolichos biflorus agglutinin (DBA) and Bandeieraea simplicifolia agglutinin 1 (BS 1) in human endometrium tissue in the (a-f) early proliferative phase and the (g-j) mid-secretory phase of the menstrual cycle. $(\mathrm{a}, \mathrm{c})$ Haematoxylin-eosin staining. (b,d) Serial sections corresponding to (a) and (c) stained with UEA 1. (e,f) Low and high magnification of UEA 1 binding. UEA 1 shows 
relatively straight; however, during the secretory phase they become coiled and the thickness of the walls increases. As this remodelling occurs, it is possible that the TGF $\beta$ system plays a part in the interaction between the endothelial cells and the surrounding vascular smooth muscle cells. Endothelial cell proliferation is significantly increased in the functional layer in comparison with the basal layer (Rogers et al., 1998). Therefore, the presence of CD105 on the functional layer vessels may antagonize the inhibitory effects of TGF $\beta$ on endothelial cells. In fact, antisense inhibition of CD105 translation enhances the ability of TGF $\beta 1$ to suppress growth and migration of cultured endothelial cells and reduces the length of capillary-like structures ( $\mathrm{Li}$ et al., 2000). Spiral arteries, which supply the functional layer of the endometrium, play a key role in the initiation and control of menstrual bleeding. During normal menstrual cycles, vascular contraction increases as a result of decreasing steroid concentrations. Subsequently, ischaemia and necrosis of the functional layer and sloughing occur. Therefore, the TGF $\beta-C D 105$ system could be one of the factors involved in the development of spiral arteries, which is important in endometrial physiology.

In agreement with reports by Rees et al. (1993) and Tawia et al. (1993), the findings from the present study indicate that endothelial cells in all types of vessel are immunostained for CD31. Staining for CD34 was found on most endothelial cells. In particular, strong staining was observed on small vessels and capillaries, which is in agreement with reports by Rees et al. (1993) and Song et al. (1995). Particularly strong staining was found around glands, which may be due to a close association of a network of capillaries around the glands; however, this contention is difficult to determine precisely, as the histological appearance of such vessels is compromised due to tissue shrinkage during fixation (this is approximately $40 \%$ in material fixed in formalin). Another possibility is that the antibody is staining non-endothelial cells in the stroma around the glands. It has been suggested that non-vascular CD34-positive cells are able to form basement membrane and play a supportive role in the maturation or proliferation of adjacent stem cells (Weiss and Nickoloff, 1993; Suster and Fisher, 1997). In human endometrium, some basal cells do express CD34 (Kohnen et al., 2000).

Endothelial cells were positively stained for anti-vWF within large vessels, but staining was weak or even absent in capillaries. Song et al. (1995) reported that in women with normal menstrual cycles, the number of CD34-positive vessels was significantly higher than the number of vWF-positive vessels. This difference is probably because these two antibodies stain different populations of endothelial cells, possibly reflecting differences in the behaviour of these cells.

Vessels located close to the glands were always stained strongly with anti-CD31, CD34, vWF and UEA 1. Endometrial epithelial cells are capable of producing a variety of growth factors, some of which stimulate endothelial cell growth or migration. Vascular endothelial growth factor A (VEGF-A) mRNA is abundant in glandular epithelial cells in the luteal phase (Charnock-Jones et al., 1993, Sharkey et al., 2000), whereas its receptors, flt1 KDR, are located on endothelial cells (Millauer et al., 1993). The close association between epithelial and endothelial cells may be due to the secretion of this, or similar factors, and these capillaries may be required to support the active metabolism and secretory activity of these cells.

BS 1, DBA and PNA bind specifically to endothelial cells in some species (Plendl and Sinowatz, 1995; Plendl et al., 1995, 1996). In humans, only a few studies have described the binding of these lectins. BS 1 has been demonstrated to react with endothelium in human placenta (Lang et al., 1994; Zhang et al., in press). DBA reacted with glandular epithelial cells of endocervical adenocarcinoma, but not those of endometrial adenocarcinoma (Toda et al., 1998), although PNA reactivity was lost in endometrial adenocarcinomas (Sivridis and Agnantis, 1996). In the present study, no endothelial binding of BS 1, DBA and PNA was detected in human endometrium at any stage of the menstrual cycle. In contrast, these lectins strongly stained glandular epithelial cells and, thus, they are of little use as endothelial markers in human endometrium.

In conclusion, binding of anti-CD105, CD31, CD34, VWF and UEA 1 distinguishes between different populations of endometrial endothelial cells. Anti-CD31, anti-CD34 and UEA 1 are reliable markers for endothelial cells in human endometrium, although the precise populations stained at any one time differ. $\mathrm{VWF}$ is somewhat selective for the endothelial cells within larger vessels and antiCD105 binds specifically to endothelial cells within endometrial arterioles. The lectins BS 1, DBA and PNA do not bind to endometrial endothelial cells but do bind to glandular epithelial cells; this finding is in contrast to that in other species.

The authors would like to thank the consultant and theatre staff of Addenbrooke's Hospital, Cambridge for their help in tissue collection, and the pathology staff for their expertise in histology and staging of endometrial tissues. This work was supported by MRC Program grant G9623012 to S. K. Smith and D. S. Charnock-Jones and was performed within the MRC Reproductive Angiogenesis Cooperative Group. E. G. Zhang was supported by a Churchill College Scholarship in Science, Cambridge from the Pannett Fund.

\section{References}

Arthur HM, Ure J and Smith AJH et al. (2000) Endoglin, an ancillary TGF beta receptor, is required for extraembryonic angiogenesis and plays a key role in heart development Developmental Biology 217 42-53

positive staining in endothelial cells of all types of vessel, including $(b, d)$ large vessels and $(e, f)$ capillaries. Binding of (g) DBA, (h) PNA and (i) BS 1 was confined to the apical region of glandular epithelial cells. (j) The negative control for UEA 1. The negative controls for DBA, PNA and BS 1 were similar to that of (j), data not shown. Scale bars represent $(\mathrm{a}, \mathrm{b}, \mathrm{e}, \mathrm{g}, \mathrm{h}, \mathrm{i}, \mathrm{j}) 50 \mu \mathrm{m}$ and $(\mathrm{c}, \mathrm{d}, \mathrm{f}) 12.5 \mu \mathrm{m}$. G: gland; V: vessel. 
Augustin HG, Kozian DH and Johnson RC (1994) Differentiation of endothelial cells: analysis of the constitutive and activated endothelial cell phenotypes BioEssays 16 901-906

Bicknell R (1993) Heterogeneity of the endothelial cell Behring Institute Mitteilungen 92 1-7

Bodey B, Bodey B, Siegel SE and Kaiser HE (1998) Over-expression of endoglin (CD105): a marker of breast carcinoma-induced neovascularization Anticancer Research $183621-3628$

Bruner KL, Rogers WH, Gold LI, Korc M, Hargrove JT, Matrisian LM and Osteen KG (1995) Transforming growth factor beta mediates the progesterone suppression of an epithelial metalloproteinase by adjacent stroma in the human endometrium Proceedings National Academy of Sciences USA $927362-7366$

Bühring HJ, Müller CA, Letarte M, Gougos A, Saalmuller A, van Agthoven AJ and Busch FW (1991) Endoglin is expressed on a subpopulation of immature erythroid cells of normal human bone marrow Leukemia 5 $841-847$

Charnock-Jones DS, Sharkey AM, Rajput-Williams J, Burch D, Schofield JP, Fountain SA, Boocock CA and Smith SK (1993) Identification and localisation of alternately spliced mRNAs for vascular endothelial growth factor in human uterus and estrogen regulation in endometrial carcinoma cell lines Biology of Reproduction 48 1120-1128

Cheifetz S, Bellón T, Calés C, Vera S, Bernabeu C, Massague J and Letarte $\mathbf{M}$ (1992) Endoglin is a component of the transforming growth factorbeta receptor system in human endothelial cells Journal of Biological Chemistry 267 19 027-19030

Dagdeviren A, Muftuoglu SF, Cakar AN and Ors U (1998) Endoglin (CD105) expression in human lymphoid organs and placenta Annals of Anatomy-Anatomischer Anzeiger 180 461-469

Eisenstein R (1991) Angiogenesis in arteries: review Pharmacology and Therapeutics 49 1-19

Fina L, Molgaard HV, Robertson D, Bradley NJ, Monaghan P, Delia D, Sutherland DR, Baker A and Greaves MF (1990) Expression of the CD34 gene in vascular endothelial cells Blood 12 2417-2426

Fonsatti E, Jekunen-AP, Kairemo KJA, Coral S, Snellman M, Nicotra MR, Natali PG, Altomonte M and Maio M (2000) Endoglin is a suitable target for efficient imaging of solid tumors: in vivo evidence in a canine mammary carcinoma model Clinical Cancer Research 6 2037-2043

Gold LI, Saxena B, Mittal KR, Marmor M, Goswami S, Nactigal L, Korc M and Demopoulos RI (1994) Increased expression of transforming growth factor $\beta$ isoforms and basic fibroblast growth factor in complex hyperplasia and adenocarcinoma of the endometrium: evidence for paracrine and autocrine action Cancer Research 54 2347-2358

Gougos A and Letarte M (1988) Identification of a human endothelial cell antigen with monoclonal antibody 44G4 produced against a pre-B leukemic cell-line Journal of Immunology 141 1925-1933

Gougos A and Letarte M (1990) Primary structure of endoglin, an RGDcontaining glycoprotein of human endothelial cells Journal of Biological Chemistry $2658361-8364$

Grimwood J, Bicknell R and Rees MC (1995) The isolation, characterization and culture of human decidual endometrium Human Reproduction 10 2142-2148

Guttmacher AE, Marchuk DA and White RI, Jr (1995) Hereditary hemorrhagic telangiectasia New England Journal of Medicine 333 918-924

Hormia M, Lehto VP and Virtanen I (1983) Identification of UEA I - binding surface glycoproteins of cultured human endothelial cells Cell Biology International Reports 7 467-475

Kauma S, Matt D, Strom S, Eierman D and Turner T (1990) Interleukin-1及, human leukocyte antigen HLA-DR $\alpha$, and transforming growth factor- $\beta$ expression in endometrium, placenta and placental membranes American Journal of Obstetrics and Gynecology 163 1430-1437

Klagsbrun M and D'Amore PA (1991) Regulators of angiogenesis Annual Review of Physiology 53 217-239

Kohnen G, Campbell S, Jeffers MD and Cameron IT (2000) Spatially regulated differentiation of endometrial vascular smooth muscle cells Human Reproduction 15 284-292

Lang I, Hahn T, Dohr G, Skofitsch G and Desoye G (1994) Heterogeneous histochemical reaction pattern of the lectin Bandeiraea (Griffonia) simplicifolia with blood vessels of human full term placenta Cell and Tissue Research 278 433-438

Lastres P, Bellon T, Cabenas C, Sanchez-Madrid F, Acevedo A, Gougos A Letarte $\mathbf{M}$ and Bernabeu $\mathbf{C}$ (1992) Regulated expression on human macrophages of endoglin, an Arg-Gly-Asp-containing surface antigen European Journal of Immunology 22 393-397

Letarte M, Greaves A and Vera S (1995) Endoglin. In Leukocyte Typing, V pp 1756-1759 Eds SF Schlossman, L Baumsell and W Gilks. Oxford University Press, Oxford

Li CG, Hampson IN, Hampson L, Kumar P, Bernabeu C and Kumar S (2000) CD105 antagonizes the inhibitory signaling of transforming growth factor beta 1 on human vascular endothelial cells FASEB Journal 14 55-64

McCarthy SA, Kuzu I, Gatter KC and Bicknell R (1991) Heterogeneity of the endothelial cell and its role in organ preference of tumor metastasis Trends in Pharmacological Science 12 462-467

Millauer B, Wizigmann-Voos S, Schnürch H, Martinez R, Moller NPH, Risau W and Ullrich A (1993) High affinity VEGF binding and developmental expression suggest Flk-1 as a major regulator of vasculogenesis and angiogenesis Cell 72 835-846

Nikitenko LL, MacKenzie IZ, Rees MC and Bicknell R (2000) Adrenomedullin is an autocrine regulator of endothelial growth in human endometrium Molecular Human Reproduction 6 811-819

Pepper MS, Vassalli JD, Orci L and Montesano R (1993) Biphasic effect of transforming growth factor- $\beta 1$ on in vitro angiogenesis Experimental Cell Research 204 356-363

Plendl J and Sinowatz F (1995) Fetal versus adult brain endothelium in vitro: characterisation and reaction to tumor-conditioned medium Electronic Journal of Pathology and Histology 1 28-39

PlendI J, Sinowatz F and Auerbach R (1995) A transformed murine myocardial vascular endothelial cell clone: characterisation of cells in vitro and of tumors (derived from the clone) in situ. Virchows Archiv 426 619-628

Plendl J, Neumüller C, Vollmar A, Auerbach R and Sinowatz F (1996) Isolation and characterization of endothelial cells from different organs of fetal pigs Anatomy and Embryology 194 445-456

Rees MC, Heryet AR and Bicknell R (1993) Immunohistochemical properties of the endothelial cells in the human uterus during the menstrual cycle Human Reproduction 8 1173-1178

Robledo MM, Hidalgo A, Lastres P, Arroyo AG, Bernabeu C, SanchezMadrid F and Teixido J (1996) Characterization of TGF-beta 1-binding proteins in human bone marrow stromal cells British Journal of Haematology 93 507-514

Rogers PA, Lederman F and Taylor N (1998) Endometrial microvascular growth in normal and dysfunctional states Human Reproduction 4 503-508

Sharkey AM, Day K, McPherson A, Malik S, Licence D, Smith SK and Charnock-Jones DS (2000) Vascular endothelial growth factor expression in human endometrium is regulated by hypoxia Journal of Clinical Endocrinology and Metabolism 85 402-409

Sivridis E and Agnantis N (1996) The loss of reactivity from human endometrium is a feature of malignant change Pathology Research and Practice 192 989-997

Sixma JJ and DeGroot PG (1991) von Willebrand factor and the blood vessel wall Mayo Clinic Proceedings 66 628-633

Song JY, Markham R, Russell P, Wong T, Young L and Fraser IS (1995) The effect of high-dose medium and long-term progestogen exposure on endometrial vessels Human Reproduction 10 797-800

St Jacques S, Forte M, Lye SJ and Letarte M (1994) Localisation of endoglin, a transforming growth factor-beta binding protein, and of CD44 and integrins in placenta during the first trimester of pregnancy Biology of Reproduction 51 405-413

Suster S and Fisher C (1997) Immunoreactivity for the human hematopoietic progenitor cell antigen (CD34) in lipometous tumors American Journal of Surgical Pathology 21 195-200

Tawia SA, Beaton LA and Rogers PA (1993) Immunolocalisation of the cellular adhesion molecules, intercellular adhesion molecule-1 (ICAM-1) and platelet endothelial cell adhesion molecule (PECAM) in human endometrium throughout the menstrual cycle Human Reproduction 8 175-181

Thorpe PE and Burrows FJ (1995) Antibody-directed targeting of the 
vasculature of solid tumors Breast Cancer Research and Treatment 36 237-258

Toda T, Sadi AM, Egawa H, Atari E, Qureshi B and Nagai Y (1998) Affinity of four lectins for endocervical and endometrial non-neoplastic and neoplastic glandular epithelium Histopathology 32 257-263

Traweek ST, Kandalaft PL, Mehta P and Batlifora H (1991) The human hematopoietic progenitor cell antigen (CD34) in vascular neoplasia American Journal of Clinical Pathology 96 25-31

Weiss SW and Nickoloff BJ (1993) CD34 is expressed by a distinctive cell population in peripheral nerves, nerve sheath tumors and related lesions American Journal of Surgical Pathology 17 1039-1045

Wells M (1996) Female genital tract. In General and Systemic Pathology 2nd Edn. pp 551-584 Ed. JCE Underwood. Churchill Livingstone, Edinburgh
Wrana JL, Attisano L, Wieser R, Ventura F and Massague J (1994) Mechanism of activation of the TGF- $\beta$ receptor Nature (London) 370 341-347

Zhang EG, Burton JG, Smith SK and Charnock-Jones DS Placental vessel adaptation during gestation and to high altitude: changes in diameter and perivascular cell coverage Placenta $\mathbf{2 3}$ (in press)

Received 2 May 2002.

First decision 2 July 2002.

Revised manuscript received 22 July 2002.

Accepted 1 August 2002. 
